\title{
Article
}

\section{Oral rehydration salts therapy use among children under five years of age with diarrhea in Ethiopia}

\author{
Nasser B. Ebrahim, ${ }^{1}$ Madhu S. Atteraya ${ }^{2}$ \\ ${ }^{1}$ Department of Public Health; ${ }^{2}$ Department of Social Welfare, Keimyung University, Dalseo-Gu, Daegu, South \\ Korea
}

\begin{abstract}
Background: Oral rehydration salts (ORS) therapy for diarrheal diseases is considered an effective therapy that can be applied in many resource-poor settings. Nevertheless, it has been consistently underutilized, and as a result, its potential to reduce child mortality has not been fully exploited. In Ethiopia, the use of ORS therapy for children under five has been inadequate. Like any other health behavior, the provision of ORS therapy to children during diarrheal episodes by caregivers is complex and context dependent. Identifying the factors may help promote wider application.

Design and methods: We used data from the 2016 Ethiopia Demographic and Health Survey (EDHS-2016). Samples were selected by a two-stage stratified cluster sampling method. We used data on children under five years of age whose mothers (aged 15-49 years) reported that the child had had diarrhea within two weeks before the survey was conducted $(n=1221)$. The dependent variable was whether these children received ORS therapy. The contextual independent factors were socio-demographic variables (mothers' age, child's age, child's sex, child's place of residence, household wealth, and mother/ husband/partner's education levels and work status), as well as media exposure and healthcare utilization.
\end{abstract}

Results: The prevalence of ORS therapy use among the children was $30 \%$. Mothers who had made at least four prenatal visits during their last pregnancy were $87 \%$ more likely to use ORS therapy for their children than those who had fewer prenatal visits (OR=1.874; CI: $1.140-3.082 ; \mathrm{p}=0.013)$.

Conclusions: Integrating efforts for scaling-up ORS use with prenatal health care services may have an extra benefit of promoting children's wellbeing and survival.

\section{Introduction}

Worldwide, diarrhea is the second leading cause of mortality among children under five years of age and claims the lives of 525,000 children annually. ${ }^{1,2}$ The overwhelming majority $(90 \%)$ of deaths from diarrhea in 2016 occurred in Sub-Saharan Africa and South $\mathrm{Asia}^{3}{ }^{3}$ disproportionately affecting children living in areas with poor sanitation, unsafe water, and inadequate access to health services. ${ }^{4}$ As well, in Ethiopia, diarrheal diseases are the second leading cause of under-five mortality. ${ }^{4}$ Most of these deaths can be prevented through cost-effective interventions that can easily be applied in resource-poor settings. ${ }^{1,5,6}$ Diarrheal diseases cause death by severe dehydration and fluid loss, as well as through the systemic blood infections sometimes associated with them. ${ }^{2}$ Beyond causing significant mortality and morbidity, diarrheal diseases can negatively impact children's early growth, perhaps by interfering with nutrient absorption. ${ }^{7}$

The World Health Organization's Integrated Management of Childhood Illness (IMCI) guidelines recommend that diarrhea case management include oral rehydration therapy (ORT) in conjunction with continuous breast feeding and zinc supplementation to prevent lethal outcomes of diarrheal episodes among children. ${ }^{8}$ ORT entails the use of oral rehydration salts (ORS) and recommended home fluids. ${ }^{9}$ ORS is considered a lynchpin of ORT and has been reported to prevent $93 \%$ of mortalities from diarrhea, ${ }^{9}$ which has significantly contributed to the decline in mortality from diarrheal diseases among children. ${ }^{6}$ ORS were discovered half a century ago and have been widely available for decades. Nevertheless, despite the therapy's remarkable health outcomes, it is consistently underutilized, ${ }^{10}$ with $62 \%$ of children in low and middle-income countries still not receiving ORS treatment for diarrheal diseases. ${ }^{1}$ Similarly, results from the 2016 Ethiopia Demographic and Health Survey (EDHS-2016) showed that among children under five with diarrhea, only $30 \%$ received ORS therapy. ${ }^{11}$

\section{Significance for public health}

In Ethiopia, diarrheal diseases are the second leading cause of death among children under five years of age. One of the United Nation's Sustainable Development Goals is aimed at substantially reducing preventable child mortality by 2030. Oral rehydration salts (ORS) therapy is the most effective intervention for diarrheal case management, but it is consistently underutilized. Understanding the contextual factors of caregivers of children and their association with ORS use in children under five may help achieve wider use. Our results show that ORS therapy use for children under five with diarrhea was inadequate at just 30\%. We also found that women who had visited prenatal health facilities four times or more during their last pregnancies were 87\% (OR=1.874; CI: 1.140-3.082; $p=0.013$ ) more likely to use ORS therapy for their children with diarrhea than women with fewer prenatal visits. In scaling-up ORS therapy, integrating efforts with prenatal health care services for pregnant women may contribute to expanded use and improved child survival. 
Like any other health behavior, the provision of ORS therapy to children during diarrheal episodes by caregivers is complex and context dependent. Contextual factors could have the potential to influence the manifestation of this behavior. Hence, we aimed to assess the association between contextual factors of caregivers (socio-demographic factors, media exposure, and health care utilization) and their use of ORS therapy for children under five with diarrhea from a nationally representative sample in Ethiopia. Our study may have the potential to contribute to expanding the use of ORS therapy in children suffering from diarrheal diseases and improving their survival.

\section{Methods}

\section{Sample design}

We used data from EDHS-2016, which is typically conducted every five years, provides key demographic and health indicators at the national level. Samples were selected by a two-stage stratified cluster sampling method. In the first stage, 645 sampling units also called enumeration areas (EAs) which included 202 and 443 urban and rural sites, respectively, were selected through probability sampling method. In the second stage, equal probability systematic sampling was used to select 28 households per cluster. ${ }^{12}$ The sampling method and ethical considerations in conducting the survey have been detailed in a report by the Central Statistical Agency of Ethiopia. ${ }^{11}$ We used data from children under five years of age whose mothers (aged 15-49 years) reported that their children had diarrhea within two weeks before the survey was conducted $(n=1221)$. However, mothers were not asked the number of bowel movements or the extent of decrease in stool consistencies. ${ }^{11}$ The response rate for the face-to face EDHS-2016 was $98 \%$ and data on non-respondents were not available. ${ }^{11}$ Using G*Power software, we ran post hoc power analysis. Assuming small effect size $(\mathrm{OR}=1.68)$ and $30 \%$ proportion of cases (ORS prevalence) and an alpha level of 0.05 , a sample size of 1221 had enough statistical power, i.e. $93 \%$ probability of detecting significant differences between variables.

\section{Measurements}

The dependent variable was whether the children received (ORS) therapy. The contextual independent factors were sociodemographic variables (mothers' age, child's age, child's sex, child's place of residence, household wealth, and mother/ husband/partner's education levels and work status), as well as media exposure and healthcare utilization. Descriptions of variables and categories are presented in Table 1 .

\section{Data analysis}

For the data analysis, we used a module for complex data analysis in SPSS v. 25.0. Sampling weights were applied, and effects associated with the complex survey design were accounted for. Descriptive statistical analyses were run, and bivariate associations were tested by the chi-square statistic for variables in the study (socio-demographic variables, media exposure and heath care utilization). In the multivariate analysis, independent variables that showed bivariate associations with the dependent variable with $\mathrm{p}<0.3$ were chosen for further analysis and examined by a multivariate logistic regression model. A p-value of less than 0.05 was used to determine statistical significance.

\section{Results}

The prevalence of ORS therapy use among children under five years of age who had diarrhea within two weeks before the survey was $30 \%$ (Table 2). At the bivariate level, the mother's age, place of residence, and number of prenatal visits were significantly associated with ORS therapy. The rest of the variables showed no significant associations with ORS therapy use (Table 2). At the multivariate level, the only variable that showed a significant association $(\mathrm{OR}=1.874$; $\mathrm{CI}$ : 1.140-3.082; $\mathrm{p}=0.013)$ with ORS therapy for children was prenatal health care utilization by the mothers in their last pregnancies. Mothers who had made at least four prenatal visits during their last pregnancy were $87 \%$ more likely to use ORS

\section{Table 1. Variable description and categorization}

\begin{tabular}{|c|c|c|}
\hline Variable & Descriptions & Categories \\
\hline $\begin{array}{l}\text { Dependent variable } \\
\text { Received oral rehydration salts (ORS) therapy }\end{array}$ & $\begin{array}{l}\text { Children under-five who whose mothers } \\
\text { reported to have diarrhea 2-weeks before survey }\end{array}$ & $\begin{array}{l}\text { Received no ORS therapy=0; Received ORS } \\
\text { therapy }=1\end{array}$ \\
\hline $\begin{array}{l}\text { Independent variables } \\
\text { Mother's age } \\
\text { Child age under } 5 \\
\text { Child sex } \\
\text { Residence } \\
\text { Household wealth }\end{array}$ & $\begin{array}{l}\text { Mother age in years } \\
\text { Child age in months } \\
\text { Male/ female } \\
\text { Rural/urban } \\
\text { Wealth index (generated from household income, } \\
\text { consumption, and expenditures) }\end{array}$ & $\begin{array}{l}15-24=0 ; 25-34=1,35-49=2 \\
0-11=0 ; 12-35=1 ; 36-59=2 \\
\text { Male }=1 ; \text { female }=0 \\
\text { Rural }=0 ; \text { urban }=1 \\
\text { Poor }=0 ; \text { middle }=1 ; \text { rich }=2\end{array}$ \\
\hline $\begin{array}{l}\text { Educational level } \\
\text { Employment status }\end{array}$ & $\begin{array}{l}\text { Mother/husband/partner's education } \\
\text { Mother/husband/partner's employment status }\end{array}$ & $\begin{array}{l}\text { No education }=0 ; \text { primary }=1 ; \\
\text { secondary and higher }=2 \\
\text { Unemployed }=0 ; \text { employed }=1\end{array}$ \\
\hline Media exposure & $\begin{array}{l}\text { Frequency of reading newspaper or magazine } \\
\text { Frequency of listening to radio } \\
\text { Frequency of watching television }\end{array}$ & $\begin{array}{l}\text { No exposure }=0 \\
\text { any exposure }=1\end{array}$ \\
\hline $\begin{array}{l}\text { Health care utilization } \\
\text { Prenatal care visit* }\end{array}$ & Number of antenatal visits in the last pregnancy & $\begin{array}{l}0-3 \text { visits during pregnancy }=0 \\
\geq 4 \text { visits during pregnancy }=1\end{array}$ \\
\hline Health care visit for any service & Visited health facility in the last 12 months & $\mathrm{No}=0 ; \mathrm{Yes}=1$ \\
\hline
\end{tabular}

The new WHO guidelines increased contacts between pregnant women and provider from four to eight; ${ }^{13}$ however, we used the previous guidelines of at least four visits of antenatal care during pregnancy because of the limited number of women who at least had eight contacts and used ORS therapy for children. 
therapy for their children with diarrhea than mothers who had fewer prenatal visits. However, mothers visiting a health care facility for general health purposes was not associated with ORS use for their children with diarrhea (Table 3).

\section{Discussion}

The prevalence of ORS therapy among children under five with diarrhea was $30 \%$, meaning only one in three children under five with diarrhea receive ORS therapy in Ethiopia. Nonetheless, the lower use in Ethiopia is on par with the global and African averages ${ }^{6}$ which is revelatory of the underutilization of this costeffective treatment throughout the world. ${ }^{12}$ Barriers cited for expanding the use of ORS therapy include cost, lack of awareness, and availability. ${ }^{13-16}$ The United Nation's Sustainable Development Goals (SDGs) target the end of preventable mortality for neonates and children under five by $2030 .{ }^{17}$ For example, in India, public and private sectors were involved in targeting demand and supply barriers for ORS therapy - a strategy that boosted ORS therapy coverage,${ }^{6}$ could as well help Ethiopia achieve child survival SDGs.

The lack of significant associations between the use of ORS therapy and all the variables in the study except the mothers' use of prenatal health services indicate the universality of ORS underutilization by different segments of the study population. Also, our preliminary analysis showed no significant difference between breastfeeding and non-breastfeeding mothers' in the use of ORS for their children. Among interventions to increase ORS therapy

Table 2. Contextual factors related to ORS therapy use in children under 5 who had diarrhea in the 2-weeks before the survey.

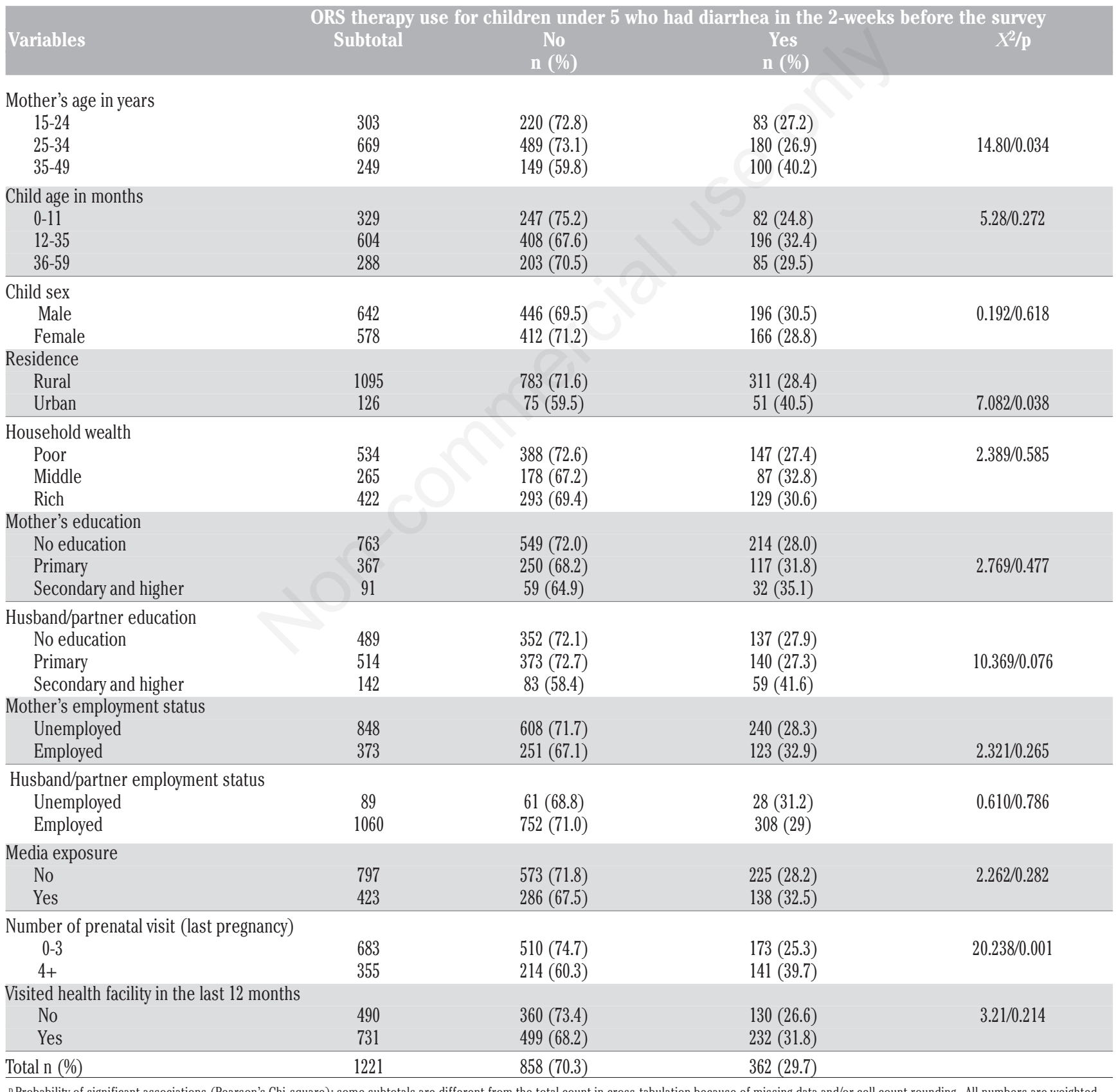


coverage, integrating ORS use efforts in the existing health services has been suggested. ${ }^{18}$ Among the contextual factors examined in this study, only prenatal health care utilization by mothers was significantly $(\mathrm{OR}=1.874 ; \mathrm{CI}: 1.140-3.082 ; \mathrm{p}=0.013)$ associated with ORS use in children. Women who had visited prenatal services four times or more during their last pregnancy were $87 \%$ more likely to use ORS therapy for their children with diarrhea. However, visiting health care facility for other purposes was not associated with increased likelihood of using ORS therapy. Hence, integrating ORS scaling-up efforts with expanded prenatal health care services for pregnant women may have extra benefit of promoting children's wellbeing and survival. The EDHS-2016 results showed that only $32 \%$ of the women had visited prenatal care centers at least four times during their last pregnancy. ${ }^{11}$ Thus, there is a huge potential for expanding prenatal health services and improving child survival. Main barriers that could constrain prenatal health care utilization in Ethiopia include widespread nonavailability of the services, long distance to health facilities, and lower women's decision-making autonomy. ${ }^{19}$ Addressing these barriers may as well enhance ORS use among children. Ultimately, risk reduction for diarrheal diseases should focus on promoting good sanitation and safe drinking water. Nonetheless, expanded use of ORS therapy coverage is needed to further reduce preventable child mortality in Ethiopia.

\section{Study strengths and limitations}

Unlike previous studies, one of the strengths of this study is that the results can be generalized to the Ethiopian population at

Table 3. Adjusted odd-ratios (OR) and $95 \%$ confidence $(95 \% \mathrm{CI})$ : ORS therapy use for children under 5 who had diarrhea in the 2weeks before the survey

\begin{tabular}{|c|c|c|c|}
\hline Variables & OR & $95 \%$ CI & p \\
\hline $\begin{array}{l}\text { Mother's age in years } \\
15-24 \\
25-34 \\
35-49\end{array}$ & $\begin{array}{c}1 \\
0.850 \\
1.490\end{array}$ & $\begin{array}{l}0.483-1.495 \\
0.773-2.874\end{array}$ & 0.093 \\
\hline $\begin{array}{l}\text { Child age in months } \\
0-11 \\
12-35 \\
36-59\end{array}$ & $\begin{array}{c}1 \\
1.443 \\
1.527\end{array}$ & $\begin{array}{l}0.900-2.315 \\
0.759-3.073\end{array}$ & 0.288 \\
\hline $\begin{array}{r}\text { Residence } \\
\text { Rural } \\
\text { Urban }\end{array}$ & $\begin{array}{c}1 \\
1.116\end{array}$ & $0.573-2.17$ & 0.747 \\
\hline $\begin{array}{l}\text { Husband/partner educatior } \\
\text { No education } \\
\text { Primary } \\
\text { Secondary and higher }\end{array}$ & $\begin{array}{c}1 \\
0.874 \\
1.336\end{array}$ & $\begin{array}{l}0.531-1.436 \\
0.698-2.557\end{array}$ & 0.396 \\
\hline $\begin{array}{l}\text { Mother's employment stat } \\
\text { Unemployed } \\
\text { Employed }\end{array}$ & $\begin{array}{c}1 \\
1.027\end{array}$ & $0.653-1.613$ & 0.909 \\
\hline $\begin{array}{l}\text { Media exposure } \\
\text { Yes } \\
\text { No }\end{array}$ & $\begin{array}{c}1 \\
1.170\end{array}$ & $0.718-1.906$ & 0.528 \\
\hline $\begin{array}{l}\text { Number of antenatal visits } \\
0-3 \\
4+\end{array}$ & $\begin{array}{c}\text { regnan } \\
1 \\
1.874\end{array}$ & $1.140-3.082$ & 0.013 \\
\hline $\begin{array}{l}\text { Visited health facility in the } \\
\text { No } \\
\text { Yes }\end{array}$ & $\begin{array}{c}2 \text { montl } \\
1 \\
1.242\end{array}$ & $0.768-2.007$ & 0.376 \\
\hline
\end{tabular}

large because we used a nationally representative sample with very good data quality control procedures and processes. Moreover, we used data on mothers' self-reported use of ORS for children with diarrhea just two weeks before the survey was conducted, which substantially reduces the recall bias inherent in surveys when past experiences are probed. However, our study has limitations similar to those of other studies based on cross-sectional data. In addition, mothers were not asked the number of bowel movements or extent of decrease in stool consistencies. As well, mothers' ORS use knowledge was not assessed.

\section{Conclusions}

The $30 \%$ prevalence of ORS use among children under five with diarrhea is inadequate. ORS use features cost-effectiveness and potential benefits of averting adverse health outcomes for children with diarrheal episodes. Thus, wider ORS coverage is invaluable. Integrating efforts for scaling-up ORS use with prenatal health care services for pregnant women may also enhance children's wellbeing and survival.

Correspondence: Nasser B. Ebrahim, Department of Public Health, Keimyung University, 1095 Dalgubeol-Daero, Dalseo-Gu, Daegu 42601, South Korea. E-mail: nasser.ebrahim9@gmail.com

Key words: Africa; Ethiopia; children; ORS; contextual factors.

Contributions: NBE, retrieved the data, planned the study, designed the analysis and wrote the manuscript; MSA, involved in data coding, identified variables in the study and helped with data analysis. All the authors have read and approved the final version of the manuscript and agreed to be accountable for all aspects of the work.

Conflict of interest: The authors declare that they have no competing interests, and all authors confirm accuracy.

Ethics approval: Standard ethical procedures were followed as detailed in the report https://dhsprogram.com/pubs/pdf/FR328/ FR328.pdf

Availability of data: The data used in the study is owned by Demographic and Health Survey (DHS) and ICF international. Standard ethical procedures were followed as detailed in the report: https://dhsprogram.com/pubs/pdf/FR328/FR328.pdf

Data used in this study can be accessed from Demographic and Health Survey (DHS) and ICF international database.

Acknowledgments: We would like to thank the Demographic and Health Survey (DHS) Program and ICF International for allowing us to use their database.

Received for publication: 3 January 2020.

Accepted for publication: 12 December 2020.

o Copyright: the Author(s), 2021

Licensee PAGEPress, Italy

Journal of Public Health Research 2021;10:1732

doi:10.4081/jphr.2021.1732

This work is licensed under a Creative Commons Attribution NonCommercial 4.0 License (CC BY-NC 4.0). 


\section{References}

1. UNICEF. Oral rehydration salts \& zinc: Market and supply update. 2018. Available from: https://www.unicef.org/supply/ index 90295.html

2. WHO. Diarrheal diseases. 2017. Available from https://www.who.int/news-room/fact-sheets/detail/diarrhoealdisease

3. GBD 2016 Causes of Death Collaborators. Global, regional, and national age-sex specific mortality for 264 causes of death, 1980-2016: a systematic analysis for the Global Burden of Disease Study 2016. Lancet 2017;390:1151-210.

4. Mills A. Health care systems in low-and middle-income countries. N Engl J Med 2014;370:552-7.

5. Awasthi S. Improving management of dehydration in children younger than 5 years in low-and-middle-income countries. Lancet Global Health 2016;4:e674-5.

6. Black RE. Progress in the use of ORS and zinc for the treatment of childhood diarrhea. J Glob Health 2019;9:010101.

7. Troeger C, Blacker BF, Khalil IA, et al. Estimates of the global, regional, and national morbidity, mortality, and aetiologies of diarrhoea in 195 countries: a systematic analysis for the Global Burden of Disease Study 2016. Lancet Infect Dis 2018;18:1211-28.

8. WHO. Handbook: IMCI Integrated Management of Childhood Illness. Geneva; 2005.

9. Munos MK, Walker CL, Black RE. The effect of oral rehydration solution and recommended home fluids on diarrhoea mortality. Int J Epidemiol 2010;39:i75-87.

10. Wagner Z, Asiimwe JB, Dow WH, Levine DI. The role of price and convenience in use of oral rehydration salts to treat child diarrhea: A cluster randomized trial in Uganda. PLoS Med2019;16:e1002734.
11. Central Statistical Agency Ethiopia, ICF International. Ethiopia Demographic and Health Survey, 2016. Addis Ababa, Ethiopia, and Rockville, Maryland, USA: CSA and ICF International. 2017. Available from: https://dhsprogram. com/pubs/pdf/FR328/FR328.pdf

12. Santosham M, Chandran A, Fitzwater S, et al. Progress and barriers for the control of diarrheal disease. Lancet 2010;376:63-7.

13. WHO. New guidelines on antenatal care for a positive pregnancy experience. 2016. Available from: https:/www.who.int/ reproductivehealth/news/antenatal-care/en/

14. Wagner Z, Shah M, Sood N. Barriers to use of oral rehydration salts for child diarrhea in the private sector: evidence from India. J Trop Pediatr 2014;61:37-43.

15. Wagner Z, Asiimwe JB, Dow WH, Levine DI. The role of price and convenience in use of oral rehydration salts to treat child diarrhea: A cluster randomized trial in Uganda. PLoS Med 2019;16:e1002734.

16. Mengistie B, Berhane Y, Worku A. Predictors of oral rehydration therapy use among under-five children with diarrhea in Eastern Ethiopia: a community based case control study. BMC Public Health 2012;12:1029.

17. UNICEF. Child survival and the SDGs: Looking ahead: Child survival and the Sustainable Development Goals. 2019. Available from: https://data.unicef.org/topic/child-survivalchild-survival-sdgs/

18. Schroder K, Battu A, Wentworth L, et al. Increasing coverage of pediatric diarrhea treatment in high-burden countries. J Glob Health 2019;9:0010503.

19. Tegegne TK, Chojenta C, Getachew T, et al. Antenatal care use in Ethiopia: a spatial and multilevel analysis. BMC Pregnancy Childbirth 2019;19:399. 